\title{
Oestradiol enhances tumour regression induced by B7-I/IL-2 adenoviral gene transfer in a murine model of breast cancer
}

\author{
C Dabrosin*,', K Palmer' and J Gauldie' \\ 'Department of Pathology and Molecular Medicine, Centre for Gene Therapeutics, McMaster University, Hamilton, Ontario, Canada L8N 3Z5
}

The majority of breast cancers are oestrogen dependent and although current treatment strategies have improved, approximately $50 \%$ of the patients will develop metastasis. New treatments that result in long-term systemic immunity are therefore being developed. We have previously shown that adenoviral gene transfer of B7-I/IL-2 to murine breast cancer induces a high rate of complete tumour regression and systemic immunity. Since oestrogens not only affect breast cancer but also have been shown to modulate immune function and secretion of immune-regulatory cytokines, we explored whether administration of oestradiol altered the immune response induced by an adenoviral vector expressing B7-I/IL-2. An oestrogen-dependent murine breast cancer tumour was used in ovariectomised mice, supplemented either oestradiol or placebo. We report the somewhat unexpected finding that intratumoral injection of adenovirus expressing B7-I/IL-2 induces complete tumour regression in 76\% of oestradiol-supplemented mice, while only $18 \%$ of the tumours regressed in the oestrogen-depleted group. Cured mice in both groups exhibited a similar CTL response against the tumour antigen. However, intratumoral IFN- $\gamma$ levels, 2 days after B7-I/IL-2 injection, were significantly higher in mice treated with oestradiol compared to placebo. This may be one mechanism explaining the higher response rate of tumours in oestradiol-replenished mice.

British Journal of Cancer (2003) 89, 385 - 390 doi: I 0.1038/sj.bjc.660 I099 www.bjcancer.com

(c) 2003 Cancer Research UK

Keywords: immunotherapy; mammary cancer; polyomavirus; sex steroids; adenovirus

Breast cancer accounts for almost $30 \%$ of all cancer cases in women in the Western World and the incidence of the disease is still increasing (Ries et al, 2001). Oestrogen exposure plays an important role in the risk of developing breast cancer. Prolonged exposure of sex steroids increase the risk, while surgically induced menopause by bilateral ovariectomy reduces the risk of the disease (Schairer et al, 1997; Rossouw et al, 2002). Approximately $70 \%$ of all breast cancers express the oestrogen receptor (ER), and treatments designed to block oestrogen effects in the breast are important options in the clinic (Lapidus et al, 1998). However, $50 \%$ of women with primary tumours will develop metastasis and eventually die from the disease (Klijn et al, 1992). Therefore, new treatments such as immunogene therapy that results in long-term systemic immunity, which may prevent metastatic disease, are being developed.

Gene therapy enhancing the immune response against cancer cells includes immunisation, introduction of cytokines and expression of T-cell costimulatory molecules. Presentation of antigen to the T-cell receptor is necessary for the initiation of an immune response. However, additional molecules expressed on antigen-presenting cells deliver essential costimulatory signals and in the absence of costimulation T-cell anergy is developed. The B7 costimulatory molecules B7-1 (CD80) and B7-2 (CD86) are

*Correspondence: Dr C Dabrosin, Division of Gynecologic Oncology, Faculty of Health Sciences, University Hospital, SE-58I 85 Linköping, Sweden; E-mail: lotda@imk.liu.se

Received 22 January 2003; revised I 4 April 2003; accepted I May 2003 required for full activation of $\mathrm{T}$ cells. The $\mathrm{B} 7$ molecules are members of the immunoglobulin (Ig) superfamily and are ligands for CD28 and CTLA-4 counter-receptors on T cells (Brunet et al, 1987; Freeman et al, 1989, 1991; Linsley et al, 1990). Ligation of CD28 with B7-1 or B7-2 results in upregulation of the IL-2 receptor $\alpha, \beta$ and $\gamma$ chains (Cerdan et al, 1992, 1995), increased IL-2 gene transcription (Fraser et al, 1991), upregulation of CTLA-4 mRNA levels (Lindsten et al, 1993), cytokine secretion and T-cell proliferation (Linsley et al, 1991; Freeman et al, 1993; Chambers, 2001). Expression of B7 family members in murine tumour models has been shown to activate CD8 $+\mathrm{T}$ cells and/or CD4 $+\mathrm{T}$ cells against tumour cells (Freeman et al, 1991, 1993; Townsend and Allison, 1993). Administration of IL-2 has been shown to promote antitumour immunity, presumably by alleviating the anergic block seen in T cells in some tumour models and thereby preventing the onset of anergy (Schwartz, 1990). We have previously shown that an adenovirus vector expressing human IL-2 causes complete tumour regression in approximately $20-40 \%$ of the cases, whereas a simultaneous expression of B7-1 and IL-2 in a single vector have a much higher success rate, $>90 \%$ (Emtage et al, 1998).

There are known gender differences in the immune response. Women have an increased incidence of autoimmune diseases and a better outcome after sepsis or trauma and oestrogens have been shown to modulate immune function (Ansar Ahmed et al, 1985; Schroder et al, 1998). Oral contraceptives and pregnancy alter the course of many autoimmune diseases in women (Paavonen, 1994). It has also been shown that oestrogens can regulate the expression of IL-2, IL-6, IL-10 and IFN- $\gamma$ in several cell systems (Gilmore et al, 
1997; Correale et al, 1998; Keck et al, 1998; Rogers and Eastell, 1998).

Given the impact oestrogens have on both breast cancer and the immune function, the objective of this study was to explore whether oestradiol altered the immune response induced by intratumoral injection of an adenoviral vector expressing B7-1/IL2 , in a murine oestrogen-dependent model of breast cancer.

In this study, we used ovariectomised mice supplemented with physiologic levels of oestradiol or left oestrogen depleted. We demonstrate that oestradiol supplementation results in markedly enhanced tumour regression and that this is associated with raised levels of intratumoral IFN- $\gamma$.

\section{MATERIALS AND METHODS}

\section{Animals and ovariectomy of mice}

$\mathrm{FVB} / \mathrm{n}$ mice (6-8 weeks old) were purchased from Charles River (Troy, NY, USA). They were housed in pathogen-free conditions with a light/dark cycle of $12 / 12 \mathrm{~h}$ and fed with rodent chow and water ad libitum. The McMaster University animal ethics research board approved all animal work, which was conducted according to the UKCCCR guidelines (Workman et al, 1998).

Mice were anaesthetised with isofluorane (Abbot), ovariectomised (OVX) and 3 -mm pellets containing $17 \beta$-oestradiol (E2), $0.18 \mathrm{mg}$ per 60 day release, or placebo pellets (Innovative Research of America, Sarasota, FL, USA) were implanted subcutaneously (s.c.) in the animal's back 7 days before tumour induction. The pellets provide continuous release of E2 at serum concentrations of $150-250 \mathrm{pM}$, confirmed by serum analysis assayed by Abbot Axsym Systems (Abbot, IL, USA), which is in the range of physiologic levels seen in mice during the oestrous cycle (Loeb and Qiumby, 1987).

\section{Polyoma middle T tumour model}

Tumour cells were derived from a transgenic mouse strain expressing polyoma middle $\mathrm{T}$ (PyMT) antigen under the control of the mouse mammary tumour virus (MMTV) long-terminal repeat (Guy et al, 1992). These mice develop spontaneous adenocarcinomas of all mammary epithelium by $8-10$ weeks of age. These tumours were excised, minced and incubated at $37^{\circ} \mathrm{C}$ with gentle stirring in collagenase/dispase solution $(25 \mathrm{mg}$ collagenase $250 \mathrm{mg}$ dispase, Roche, in $100 \mathrm{ml}$ phosphate-buffered saline (PBS) to generate a single-cell suspension, stored at $-70^{\circ} \mathrm{C}$ in foetal bovine serum with $10 \%$ DMSO added. Thawed cells were placed in complete F-11 medium and were cultured until they reached confluence, usually $4-6$ days. Thereafter, $1 \times 10^{6}$ cells in $200 \mu \mathrm{l}$ PBS were injected s.c. into the right hind flank of a syngenic female FVB/n host. Tumour volume was determined by measuring length, width, and depth of the tumour weekly using a caliper.

\section{Recombinant adenoviruses}

The vector expressing both human IL-2, known to be active across species, and the murine costimulatory molecule B7-1(AdB7-1/IL$2)$, and the control vector Addl70-3 were constructed as previously described (Bett et al, 1994; Emtage et al, 1998).

\section{Intratumour vector administration and rechallenge of tumour-free mice}

Following tumour formation (tumour volume $<250 \mathrm{~mm}^{3}$ ) animals were injected intratumorally with $1 \times 10^{9} \mathrm{PFU}$ of AdB7-1/IL- 2 or control Addl70-3 vector diluted $(50 \mu \mathrm{l})$ in sterile endotoxin-free PBS and tumour growth determined weekly. In animals that showed complete regression of primary PyMT tumours, mice were rechallenged at 90 days with PyMT tumour cells by subcutaneous injection of $10^{6}$ tumour cells on the opposite flank.

\section{Cytotoxic T-cell assay}

Specific PyMT antigen cytotoxic T-cell killing was measured as previously described (Addison et al, 1998; Palmer et al, 2001). Briefly, splenocytes were obtained from mice whose tumours had regressed and had also resisted rechallenge and were restimulated for 5 days by coculture with irradiated 516MT3 cells that express the PyMT antigen. Cytotoxicity was determined by coculture with 516MT3 or PTO516 (PyMT antigen-negative cells) target cells, labelled with ${ }^{51} \mathrm{Cr}$. The percent specific lysis was calculated as follows: $100 \times$ (experimental c.p.m. - spontaneous c.p.m.) (maximal c.p.m. - spontaneous c.p.m.).

\section{Quantification of murine IFN- $\gamma$ in tumour tissue and plasma}

Tumours were removed, snap frozen in liquid nitrogen, and weighed 2 and 10 days after adenovirus administration. Tumours were homogenised in PBS containing $100 \mu \mathrm{m}$ phenylmethylsulphonyl fluoride, centrifuged and the supernatants were stored at $-70^{\circ} \mathrm{C}$ for subsequent analysis. Plasma was collected by cardiac puncture. IFN- $\gamma$ was measured using an ELISA kit (R\&D Systems, Minneapolis, MN, USA). The sensitivity was $2 \mathrm{pg} \mathrm{ml}^{-1}$. All samples were analysed in duplicates and given results are the means of each duplicate.

\section{Statistics}

Data are expressed as mean \pm s.e. $\mathrm{m}$. All given values represent the mean of the duplicate analysis of each sample. Student's $t$-test and Fisher's exact test was used as appropriate. A $P<0.05$ was considered as statistically significant.

\section{RESULTS}

\section{Enhanced tumour regression by oestradiol after intratumoral administration AdB7-1/IL-2}

We have recently characterised the oestrogenic phenotype of the PyMT model used in this study. These tumours express the ER and E2 stimulates tumour cell proliferation in vitro and tumour growth in vivo (Dabrosin et al, 2003). Moreover, E2 enhances tumour angiogenesis in vivo (Dabrosin et al, 2003). The recombinant adenovirus vector expressing murine B7-1 and human IL-2 has previously been characterised and expression of both molecules have been confirmed (Emtage et al, 1998).

Administration of $1 \times 10^{9} \mathrm{PFU}$ of the B7-1/IL-2 vector resulted in complete tumour regression within 3 weeks in $76 \%$ of OVX + E2-treated animals, while only $18 \%$ of the placebo animals were cured. In the E2-treated group, all tumours showed either partial or total regression with an overall response rate of $100 \%$. Partial regression was defined as stasis or decrease in tumour volume 1 week after the administration of a vector, as compared with the original tumour volume before treatment. In the OVX animals without E2 supplement $60 \%$ of the tumours had a delayed tumour growth without cure and $23 \%$ of the tumours failed to respond at all. None of the tumours in OVX or OVX + E2 animals treated with the control vector Addl70-3 had any response and none of the mice were cured, a result that we previously have reported in normal cycling mice (Emtage et al, 1998) (Table 1). The survival data of all animals in this study are presented in Figure 1. As previously shown, the cytokines delivered intratumorally did mediate an effective immune response and tumour regression, whereas systemic delivered cytokines fail to induce any tumour response (Addison et al, 1995). The tumour size, 
Table I Summary of responses of PyMT tumours following intratumoral injection of AdB7-I/IL-2 and Addl70-3 in ovariectomised mice treated with placebo (OVX) or oestradiol (E2)

\begin{tabular}{lccc}
\hline Treatment & No response (\%) & Partial response (\%) & Total regression (\%) \\
\hline OVX control AddI70-3 & $5 / 5(100)$ & $0 / 5(0)$ & $0 / 5(0)$ \\
OVX+E2 control AddI70-3 & $5 / 5(100)$ & $0 / 5(0)$ & $0 / 5(0)$ \\
OVX AdB7-I/IL-2 & $5 / 22(23)$ & $13 / 22(59)$ & $4 / 22(18)$ \\
OVX+E2 AdB7-I/LL-2 & $0 / 17(0)$ & $4 / 17(24)$ & $13 / 17(76)^{*}$ \\
\hline
\end{tabular}

Partial response refers to tumours that have undergone partial regression followed by regrowth, or a delay in growth; no response refers to tumours that have continued to grow at a rate comparable to controls. $* P<0.005$ compared to OVX.

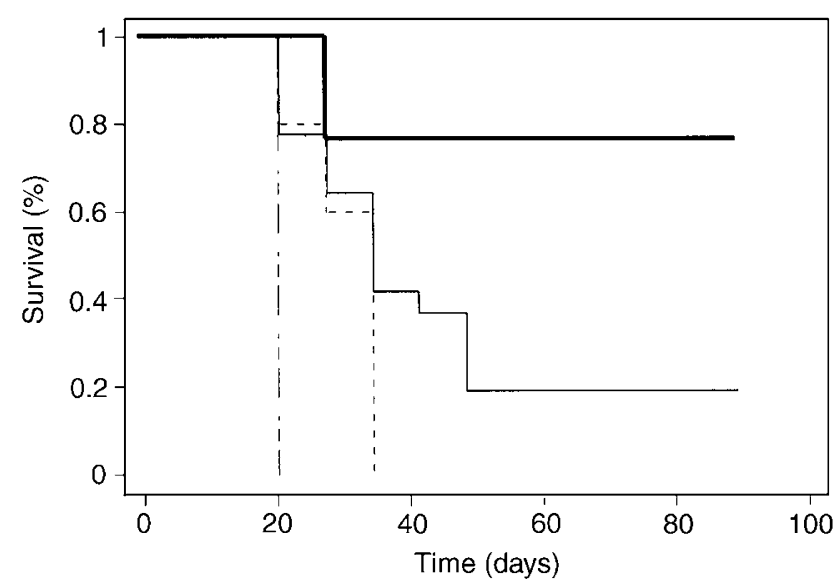

Figure I Long-term survival of ovariectomised (OVX) FVB/n mice treated with oestradiol (E2) or placebo bearing small PyMT tumours following treatment with recombinant adenovirus expressing B7-I/IL-2 or control virus Add $770-3$ at a dose of $1 \times 10^{9}$ PFU. OVX + E2-treated tumours $\left(228+60 \mathrm{~mm}^{3}\right)$ injected with AdB7-I/LL-2 $(n=17)$, OVX + placebo $\left(160 \pm 28 \mathrm{~mm}^{3}\right)$ injected with AdB7-I/IL-2 $(n=22)$. Tumours from both groups (OVX and OVX+E2, $n=|0-1|$ in each group) injected with the control virus Addl70-3, all succumbed to tumour growth. $(\longrightarrow$ AdB7-I/IL-2 OVX+E2, ( $(-)$ AdB7-I/IL-2 OVX+ placebo, (- - ) AddI70-3 OVX + E2, (- - - -) Addl70-3 OVX + placebo.

$160 \pm 28 \mathrm{~mm}^{3}$ for placebo tumours and $228 \pm 60 \mathrm{~mm}^{3}$ E2-treated tumours, was in the range previously described by our lab using B7-1/IL-2 and other cytokines delivered to PyMT tumours by adenoviral vectors (Addison et al, 1998; Emtage et al, 1998; Palmer et al, 2001).

A few tumours in each group were allowed to grow considerably larger before AdB7-1/IL-2 injection, OVX + placebo $1170 \pm 60 \mathrm{~mm}^{3}$ and $\mathrm{E} 2$ tumours $1150 \pm 132 \mathrm{~mm}^{3}$. In these larger tumours, a partial regression was induced by AdB7-1/IL-2 delivery to E2-treated mice, while placebo mice continued to grow without delay (Figure 2).

\section{Oestradiol increased intratumoral IFN $-\gamma$ production induced by AdB7-1/IL-2}

At 2 days after intratumoral administration of AdB7-1/IL-2, both E2-exposed tumours and placebo tumours had increased levels of IFN- $\gamma$ compared with tumours injected with the control vector Addl70-3, $24 \pm 0.6 \mathrm{pg} \mathrm{mg}^{-1}$ tumour in AdB7-1/IL-2 vs $3 \pm 0.04 \mathrm{pg} \mathrm{mg}^{-1}$ tumour with the control vector. However, tumours from E2-treated mice had significantly higher levels of IFN- $\gamma$ compared with placebo-treated mice, $34 \pm 0.6 \mathrm{pg} \mathrm{mg}^{-1}$ tumour vs $10 \pm 0.3 \mathrm{pg} \mathrm{mg}^{-1}$ tumour, $P<0.01, n=3-4$ in each group (Figure 3 ). Tumour levels of IFN- $\gamma$ and the magnitude of the increase in responders compared to nonresponders are in line with the previous work (Bramson et al, 1996). The increased levels of IFN- $\gamma$ were localised to the tumour since both groups had similar

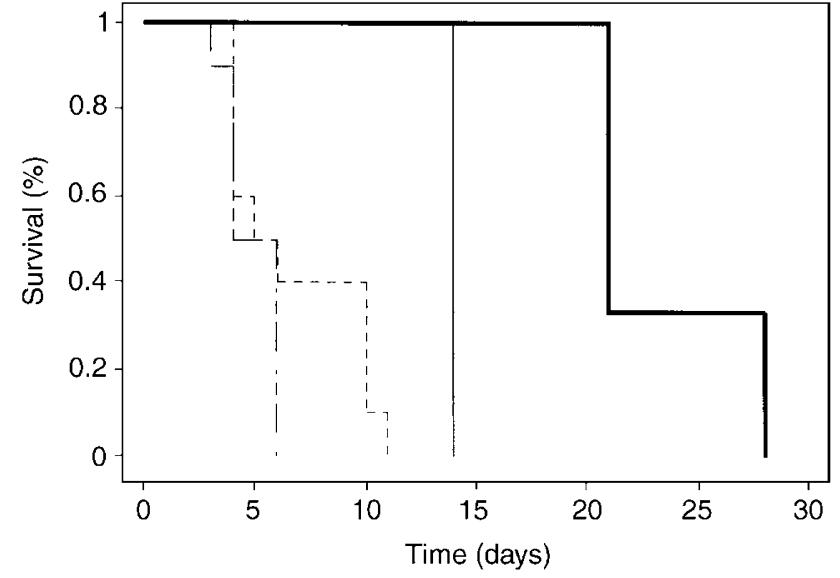

Figure 2 Survival of mice following intratumoral injection of large tumours with recombinant adenovirus expressing B7-I/IL-2. Mice treated as described in Figure I. OVX $+E 2\left(n=3\right.$, initial size $\left.1150 \pm 132 \mathrm{~mm}^{3}\right)$ and OVX + placebo $\left(n=3,1170 \pm 60 \mathrm{~mm}^{3}\right)$ were injected with $1 \times 10^{9} \mathrm{PFU}$ of AdB7-I/IL-2. Control animals were injected with AddI70-3, I $\times 10^{9}$ PFU $\left(n=10\right.$ in each group with similar tumour sizes, $1230 \pm 150 \mathrm{~mm}^{3}$, as the treated tumours). ( $\longrightarrow$ ) AdB7-I/IL-2 OVX $+\mathrm{E2},(\stackrel{-}{\longrightarrow}$ AdB7-I/IL-2 OVX+ placebo, (- - - ) Addl70-3 OVX+E2, (- - - - ) AddI70-3 OVX + placebo.

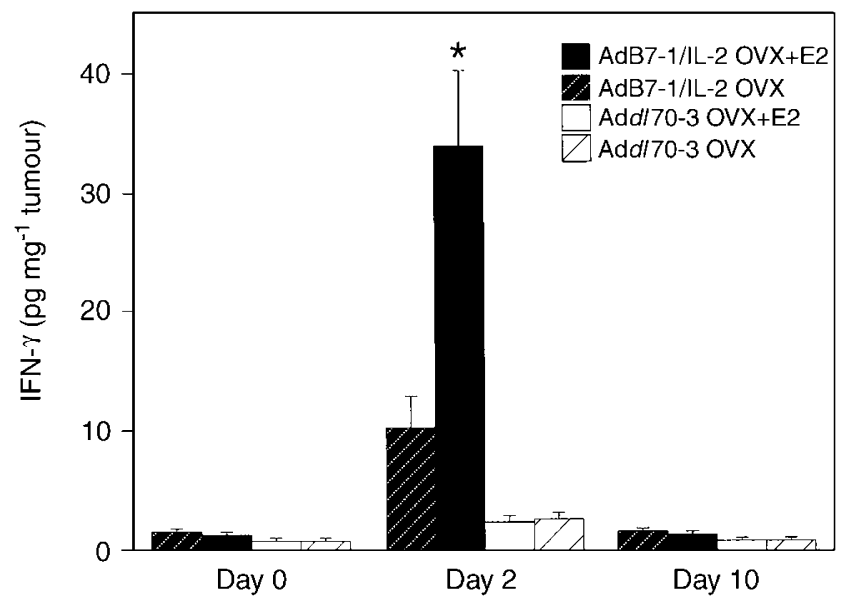

Figure 3 Oestradiol increased local IFN- $\gamma$ levels 2 days following treatment with AdB-7/IL-2. Mice treated as described in Figure I. IFN- $\gamma$ was measured in tumour homogenate and normalised to the mass of tumour. Oestradiol tumours treated with AdB7-I/IL-2 had significantly higher levels of IFN- $\gamma$ on day $2, \mathrm{OVX}+\mathrm{E} 2 n=4$, vs OVX + placebo $n=3$, $* P<0.05$. There was no difference between the groups on days 0 and 10 .

plasma levels of IFN- $\gamma, 52 \pm 5 \mathrm{pg} \mathrm{ml}^{-1}$. At 10 days after vector administration, the tumour levels of IFN- $\gamma$ in both groups had decreased to $1.4 \pm 0.02 \mathrm{pg} \mathrm{mg}^{-1}$ tumour (Figure 3 ). There was no difference between E2-treated and placebo mice in the control group (Figure 3). 


\section{Generation of long-term systemic immunity to PyMT tumour cell rechallenge}

Mice that had undergone complete regression of the PyMT tumours after treatment with AdB7-1/IL-2 were rechallenged with a second inoculation of $1 \times 109$ PyMT cells 90 days after initial vector administration, on the left hind flank. None of the challenged mice developed tumours and all remained tumour free during the observation period (90 days). Naive mice simultaneously injected with the same tumour cell suspension developed tumours within 21 days as expected. These results suggest that the cured mice in either E2 or placebo group developed long-term antitumour immunity after the AdB7-1/IL-2 treatment. These results are in line with our previous data showing that cured mice develop long-term immunity regardless of the cytokine vector used, although the different vectors exhibit higher or lower effectiveness in inducing complete tumour regression (Emtage et al, 1998; Palmer et al, 2001).

\section{CTL activity in cured mice}

To determine whether oestradiol supplement may affect the development of a tumour-specific CTL response, cured mice in both the E2 and placebo group were killed and their spleens removed 6 weeks following PyMT rechallenge. Splenocytes prepared from either group demonstrated a $50 \%$ specific lysis of 516MT3 cells, expressing the PyMT antigen, at an effector to target ratio of 90:1 (Figure 4). Minimal background was observed. This suggests the presence of significant numbers of effector cells capable of killing cells expressing the PyMT tumour antigen in both treatment groups. Splenocytes from control mice did not exhibit any tumour-specific CTL activity as previously shown (Emtage et al, 1998).

\section{DISCUSSION}

In this study, we demonstrated that oestradiol, at physiologic concentrations, enhances the immune response by intratumoral adenoviral gene delivery of B7-1/IL-2 in a murine model of breast cancer in which the growth rate is increased by oestrogen. This difference was not due to an inability of oestrogen-depleted mice

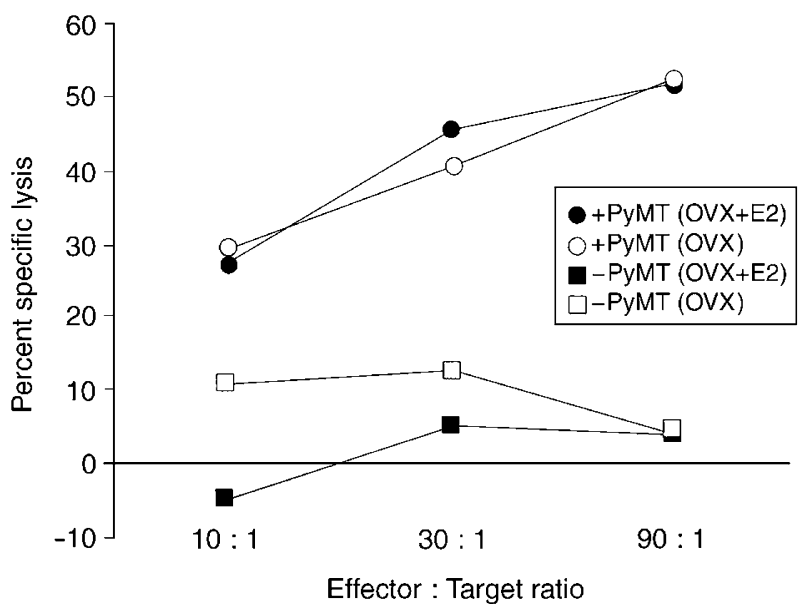

Figure 4 Cytotoxic $T$ lymphocyte activity in mice after total tumour regression induced by $A d B 7 / / L-2$ treatment. Spleens were removed from mice, which had undergone complete regression of PyMT breast cancer tumours and not developed tumours after having been rechallenged with fresh tumour cells. Splenocytes were used in a ${ }^{5} \mathrm{Cr}$ release assay against target cells (5I6MT3) with or without the PyMT antigen, PT05I 6 (-PyMT). to induce a CTL response since cured mice from both groups exhibited similar CTL activity. However, we show that oestradiol increased the local IFN- $\gamma$ response after delivery of AdB7-IL-2, which may be one mechanism to explain the higher response rate in the oestradiol-supplemented mice.

Distinct patterns of cytokine expression are associated with the development of TH1 or TH2 immune responses (Mosmann and Coffman, 1989; Mosmann and Sad, 1996). Development of CTL response involves IL-2 and IFN $\gamma$, while humoral responses are associated with IL-4, IL-6 and IL-10. IFN- $\gamma$ is important for the development of a potent antitumour response (Ogawa et al, 1998). Our previous studies with the PyMT tumour model have shown that lymphocytes isolated from cured mice exhibited raised levels of IFN- $\gamma$ indicating that treatment with Ad vectors induces cytokines and costimulatory molecules, which induce TH1mediated antitumour responses (Bramson et al, 1996; Addison et al, 1998). Moreover, IFN- $\gamma$ affects tumour cells to be more susceptible to T-cell-mediated killing (Gerrard et al, 1988) and upregulates the chemokines IP-10 (interferon-inducibleprotein) and MIG (monokine induced by gamma interferon) resulting in decreased angiogenesis (Angiolillo et al, 1995; Palmer et al, 2001). IFN- $\gamma$ also appears to sensitise human breast cancer cells to undergo apoptosis (Ruiz-Ruiz et al, 2000).

It has been suggested that females produce stronger immune reactions than males (Ansar Ahmed et al, 1985). Autoimmune diseases such as multiple sclerosis and rheumatoid arthritis are more frequent in women and patients go into a clinical remission during pregnancy and exacerbate postpartum suggesting that the immune response differs with various levels of oestrogen (Ostensen et al, 1983; Confavreux et al, 1998). Oestradiol has been found to modulate the secretion of cytokines from human $\mathrm{CD} 4+$ cells, at physiological levels oestradiol increased IFN- $\gamma$ production with no effect on IL-10 secretion (Gilmore et al, 1997). However, at pharmacological levels or levels seen in pregnancy, the IL-10 levels increased significantly, while IFN- $\gamma$ remained at the same levels seen with a low dose of oestradiol (Gilmore et al, 1997). Moreover, lymphocytes from female mice produce higher levels of IFN- $\gamma$ after immune stimulation than those from males and an oestrogen-responsive element in the IFN- $\gamma$ promoter in murine spleen cells has been found (McFarland and Bigley, 1989; Fox et al, 1991). In addition, both oestrogen and B7 molecules have the ability to activate CD8 + cytotoxic cells even in the absence of CD4 + (Stimson, 1988; Van Gool et al, 1996). However, other mechanisms may also contribute in the higher response of oestradiol treated tumours. We have recently shown that oestradiol-treated PyMT tumours used in this experiment have a higher microvessel count compared with tumours at the same size grown in OVX mice with placebo supplement (Dabrosin et al, 2003). This could affect the access of the tumour cells to the immune cells, that is, oestradiol-treated tumours have higher blood flow and are thereby more available to the immune system.

None of the larger established tumours underwent complete regression, but the tumours from oestradiol-treated mice showed a partial response and delayed tumour growth. This suggests that tumour size is a predictive factor for the success rate of immune gene therapy and that a dose adjustment or other adjuvant therapies are needed for treatment of heavy tumour burden. This is in line with current clinical principles where tumour size is a strong predictive factor for overall survival and relapse-free interval and larger tumours are treated with surgery in combination radiotherapy and/or chemotherapy (Linderholm et al, 2000; Bergh et al, 2001).

The results in our study are intriguing and somewhat unexpected since the cornerstone of treatment of oestrogendependent breast cancer is antioestrogen hormonal therapy. However, the action of oestrogen in breast cancer is complex, poorly understood and contradictory. While oestrogen stimulates tumour cell growth in vitro at low doses, it inhibits proliferation at 
high levels (Lippman et al, 1976). In vivo, breast tumours may maintain high local levels of oestrogen independent on the overall circulating concentration suggesting that added exogenous oestrogen has very little effect on the local tumour environment (Blankenstein et al, 1992). Oestrogens have the ability to affect tumour cell division, angiogenesis, bone density and the immune system, and the overall result in vivo is dependent on the balance between all these effects. Moreover, oestrogen effects are related to the dose and type of hormone used. It is therefore important to use physiologic levels of oestrogen and the naturally occurring E2 in studies of pathogenesis and immune modulation.

We conclude that oestradiol increases the cure rate of oestrogenenhanced murine breast cancer treated with an intratumoral adenoviral vector expressing B7-1/IL-2. Oestradiol treatment increased the IFN- $\gamma$ levels in tumour tissue, measured 2 days after tumour injection, which may be involved in the mechanisms

\section{REFERENCES}

Addison CL, Braciak T, Ralston R, Muller WJ, Gauldie J, Graham FL (1995) Intratumoral injection of an adenovirus expressing interleukin 2 induces regression and immunity in a murine breast cancer model. Proc Natl Acad Sci USA 92: 8522-8526

Addison CL, Bramson JL, Hitt MM, Muller WJ, Gauldie J, Graham FL (1998) Intratumoral coinjection of adenoviral vectors expressing IL-2 and IL-12 results in enhanced frequency of regression of injected and untreated distal tumours. Gene Therapy 5: 1400-1409

Angiolillo AL, Sgadari C, Taub DD, Liao F, Farber JM, Maheshwari S, Kleinman HK, Reaman GH, Tosato G (1995) Human interferon-inducible protein 10 is a potent inhibitor of angiogenesis in vivo. J Exp Med 182: $155-162$

Ansar Ahmed S, Penhale WJ, Talal N (1985) Sex hormones, immune responses, and autoimmune diseases. Mechanisms of sex hormone action. Am J Pathol 121: $531-551$

Bergh J, Jonsson P, Glimelius B, Nygren P (2001) A systematic overview of chemotherapy effects in breast cancer. Acta Oncol 40: 253-281

Bett AJ, Haddara W, Prevec L, Graham FL (1994) An efficient and flexible system for construction of adenovirus vectors with insertions or deletions in early regions 1 and 3. Proc Natl Acad Sci USA 91: $8802-8806$

Blankenstein MA, Maitimu-Smeele I, Donker GH, Daroszewski J, Milewicz A, Thijssen JH (1992) On the significance of in situ production of oestrogens in human breast cancer tissue. J Steroid Biochem Mol Biol 41: $891-896$

Bramson JL, Hitt M, Addison CL, Muller WJ, Gauldie J, Graham FL (1996) Direct intratumoral injection of an adenovirus expressing interleukin- 12 induces regression and long-lasting immunity that is associated with highly localized expression of interleukin-12. Hum Gene Ther 7: $1995-2002$

Brunet JF, Denizot F, Luciani MF, Roux-Dosseto M, Suzan M, Mattei MG, Golstein P (1987) A new member of the immunoglobulin superfamilyCTLA-4. Nature 328: $267-270$

Cerdan C, Martin Y, Courcoul M, Brailly H, Mawas C, Birg F, Olive D (1992) Prolonged IL-2 receptor alpha/CD25 expression after T cell activation via the adhesion molecules CD2 and CD28. Demonstration of combined transcriptional and post-transcriptional regulation. J Immunol 149: $2255-2261$

Cerdan C, Martin Y, Courcoul M, Mawas C, Birg F, Olive D (1995) CD28 costimulation regulates long-term expression of the three genes (alpha, beta, gamma) encoding the high-affinity IL2 receptor. Res Immunol 146: $164-168$

Chambers CA (2001) The expanding world of costimulation: the two-signal model revisited. Trends Immunol 22: 217-223

Confavreux C, Hutchinson M, Hours MM, Cortinovis-Tourniaire P, Moreau T (1998) Rate of pregnancy-related relapse in multiple sclerosis. Pregnancy in multiple sclerosis group. $N$ Engl J Med 339: $285-291$

Correale J, Arias M, Gilmore W (1998) Steroid hormone regulation of cytokine secretion by proteolipid protein-specific CD4+ $\mathrm{T}$ cell clones isolated from multiple sclerosis patients and normal control subjects. $J$ Immunol 161: 3365-3374 leading to the higher response rate in these mice. Future studies will determine whether these data are valid for human breast cancer and how the partial oestrogen agonist tamoxifen, the most commonly used antioestrogen in breast cancer treatment, affects immune-stimulatory breast cancer therapies.

\section{ACKNOWLEDGEMENTS}

This work was supported by grants from CIHR, Hamilton Health Sciences and St Joseph's Healthcare. C Dabrosin, MD, PhD, was Post Doctoral fellow from Faculty of Health Sciences, Linköping University, Sweden and in part supported by the Swedish Society of Medicine and the Swedish Institute. $\mathrm{K}$ Palmer was Edith $\mathrm{H}$ Turner Foundation Fund Research Fellow in Molecular Medicine.

Dabrosin C, Palmer K, Muller WJ, Gauldie J (2003) Estradiol promotes growth and angiogenesis in polyoma middle $\mathrm{T}$ transgenic mouse mammary tumour explants. Breast Cancer Res Treat 78: $1-6$

Emtage PC, Wan Y, Bramson JL, Graham FL, Gauldie J (1998) A double recombinant adenovirus expressing the costimulatory molecule B7-1 (murine) and human IL-2 induces complete tumor regression in a murine breast adenocarcinoma model. I Immunol 160: 2531-2538

Fox HS, Bond BL, Parslow TG (1991) Estrogen regulates the IFN-gamma promoter. J Immunol 146: $4362-4367$

Fraser JD, Irving BA, Crabtree GR, Weiss A (1991) Regulation of interleukin-2 gene enhancer activity by the $\mathrm{T}$ cell accessory molecule CD28. Science 251: $313-316$

Freeman GJ, Freedman AS, Segil JM, Lee G, Whitman JF, Nadler LM (1989) B7, a new member of the Ig superfamily with unique expression on activated and neoplastic B cells. J Immunol 143: 2714-2722

Freeman GJ, Gray GS, Gimmi CD, Lombard DB, Zhou LJ, White M, Fingeroth JD, Gribben JG, Nadler LM (1991) Structure, expression, and T cell costimulatory activity of the murine homologue of the human $\mathrm{B}$ lymphocyte activation antigen B7. J Exp Med 174: 625-631

Freeman GJ, Gribben JG, Boussiotis VA, Ng JW, Restivo Jr VA, Lombard LA, Gray GS, Nadler LM (1993) Cloning of B7-2: a CTLA-4 counterreceptor that costimulates human $\mathrm{T}$ cell proliferation. Science 262: 909-911

Gerrard TL, Dyer DR, Zoon KC, zur Nedden D, Siegel JP (1988) Modulation of class I and class II histocompatibility antigens on human $\mathrm{T}$ cell lines by IFN-gamma. J Immunol 140: $3450-3455$

Gilmore W, Weiner LP, Correale J (1997) Effect of estradiol on cytokine secretion by proteolipid protein-specific $\mathrm{T}$ cell clones isolated from multiple sclerosis patients and normal control subjects. J Immunol 158: $446-451$

Guy CT, Cardiff RD, Muller WJ (1992) Induction of mammary tumors by expression of polyomavirus middle $\mathrm{T}$ oncogene: a transgenic mouse model for metastatic disease. Mol Cell Biol 12: 954-961

Keck C, Herchenbach D, Pfisterer J, Breckwoldt M (1998) Effects of 17betaestradiol and progesterone on interleukin-6 production and proliferation of human umbilical vein endothelial cells. Exp Clin Endocrinol Diabetes 106: $334-339$

Klijn JG, Berns PM, Bontenbal M, Alexieva-Figusch J, Foekens JA (1992) Clinical breast cancer, new developments in selection and endocrine treatment of patients. J Steroid Biochem Mol Biol 43: 211-221

Lapidus RG, Nass SJ, Davidson NE (1998) The loss of estrogen and progesterone receptor gene expression in human breast cancer. $J$ Mammary Gland Biol Neoplasia 3: 85-94

Linderholm B, Grankvist K, Wilking N, Johansson M, Tavelin B, Henriksson R (2000) Correlation of vascular endothelial growth factor content with recurrences, survival, and first relapse site in primary nodepositive breast carcinoma after adjuvant treatment. J Clin Oncol 18: $1423-1431$

Lindsten T, Lee KP, Harris ES, Petryniak B, Craighead N, Reynolds PJ, Lombard DB, Freeman GJ, Nadler LM, Gray GS, Thompson CB, June CH (1993) Characterization of CTLA-4 structure and expression on human T cells. J Immunol 151: 3489-3499 
Linsley PS, Brady W, Grosmaire L, Aruffo A, Damle NK, Ledbetter JA (1991) Binding of the B cell activation antigen B7 to CD28 costimulates T cell proliferation and interleukin 2 mRNA accumulation. $J$ Exp Med 173: $721-730$

Linsley PS, Clark EA, Ledbetter JA (1990) T-cell antigen CD28 mediates adhesion with $\mathrm{B}$ cells by interacting with activation antigen B7/BB-1. Proc Natl Acad Sci USA 87: $5031-5035$

Lippman M, Bolan G, Huff K (1976) The effects of estrogens and antiestrogens on hormone-responsive human breast cancer in long-term tissue culture. Cancer Res 36: 4595 - 4601

Loeb W, Qiumby F (1987) The Clinical Chemistry of Laboratory Animals. New York: Pergamon Press

McFarland HI, Bigley NJ (1989) Sex-dependent, early cytokine production by NK-like spleen cells following infection with the $\mathrm{D}$ variant of encephalomyocarditis virus (EMCV-D). Viral Immunol 2: 205-214

Mosmann TR, Coffman RL (1989) TH1 and TH2 cells: different patterns of lymphokine secretion lead to different functional properties. Annu Rev Immunol 7: 145-173

Mosmann TR, Sad S (1996) The expanding universe of T-cell subsets: Th1, Th2 and more. Immunol Today 17: 138-146

Ogawa M, Yu WG, Umehara K, Iwasaki M, Wijesuriya R, Tsujimura T, Kubo T, Fujiwara H, Hamaoka T (1998) Multiple roles of interferongamma in the mediation of interleukin 12-induced tumor regression. Cancer Res 58: 2426-2432

Ostensen M, Aune B, Husby G (1983) Effect of pregnancy and hormonal changes on the activity of rheumatoid arthritis. Scand J Rheumatol 12: $69-72$

Paavonen T (1994) Hormonal regulation of immune responses. Ann Med 26: $255-258$

Palmer K, Hitt M, Emtage PC, Gyorffy S, Gauldie J (2001) Combined CXC chemokine and interleukin-12 gene transfer enhances antitumor immunity. Gene Therapy 8: $282-290$

Ries LAG, Eisner MP, Kosary CL, Hankey BF, Miller BA, Clegg L, Edwards BK (2001) SEER Cancer Statistics Review, 1973-1998, National Cancer Institute, www.seer.cancer.gov
Rogers A, Eastell R (1998) Effects of estrogen therapy of postmenopausal women on cytokines measured in peripheral blood. J Bone Miner Res 13: $1577-1586$

Rossouw JE, Anderson GL, Prentice RL, LaCroix AZ, Kooperberg C, Stefanick ML, Jackson RD, Beresford SA, Howard BV, Johnson KC, Kotchen JM, Ockene J (2002) Risks and benefits of estrogen plus progestin in healthy postmenopausal women: principal results From the Women's Health Initiative randomized controlled trial. JAMA 288: $321-333$

Ruiz-Ruiz C, Munoz-Pinedo C, Lopez-Rivas A (2000) Interferon-gamma treatment elevates caspase- 8 expression and sensitizes human breast tumor cells to a death receptor-induced mitochondria-operated apoptotic program. Cancer Res 60: 5673-5680

Schairer C, Persson I, Falkeborn M, Naessen T, Troisi R, Brinton LA (1997) Breast cancer risk associated with gynecologic surgery and indications for such surgery. Int J Cancer 70: 150-154

Schroder J, Kahlke V, Staubach KH, Zabel P, Stuber F (1998) Gender differences in human sepsis. Arch Surg 133: $1200-1205$

Schwartz RH (1990) A cell culture model for T lymphocyte clonal anergy. Science 248: $1349-1356$

Stimson WH (1988) Oestrogen and human T lymphocytes: presence of specific receptors in the T-suppressor/cytotoxic subset. Scand J Immunol 28: $345-350$

Townsend SE, Allison JP (1993) Tumor rejection after direct costimulation of CD8+ T cells by B7- transfected melanoma cells. Science 259: $368-370$

Van Gool SW, Zhang Y, Kasran A, de Boer M, Ceuppens JL (1996) T helperindependent activation of human $\mathrm{CD} 8+$ cells: the role of $\mathrm{CD} 28$ costimulation. Scand J Immunol 44: 21-29

Workman P, Twentyman P, Balkwill F, Balmain A, Chaplin D, Double J, Embleton J, Newell D, Raymond R, Stables J, Stephens T, Wallace J (1998) United Kingdom Co-ordinating Committee on Cancer Research (UKCCCR) Guidelines for the Welfare of Animals in Experimental Neoplasia (Second Edition). Br J Cancer 77: 1-10National Cancer Institute. www.seer.cancer.gov 